\title{
Chorionic somatomammotropin impacts early fetal growth and placental gene expression
}

\author{
K M Jeckel, A C Boyarko, G J Bouma, Q A Winger and R V Anthony \\ Animal Reproduction and Biotechnology Laboratory, Department of Biomedical Sciences, Colorado State University, Fort Collins, Colorado, USA \\ Correspondence should be addressed to R V Anthony: Russ.Anthony@Colostate.Edu
}

\section{Abstract}

Several developmental windows, including placentation, must be negotiated to establish and maintain pregnancy. Impaired placental function can lead to preeclampsia and/or intrauterine growth restriction (IUGR), resulting in increased infant mortality and morbidity. It has been hypothesized that chorionic somatomammotropin (CSH) plays a significant role in fetal development, potentially by modifying maternal and fetal metabolism. Recently, using lentiviral-mediated in vivo RNA interference in sheep, we demonstrated significant reductions in near-term ( 135 days of gestation; dGA) fetal and placental size, and altered fetal liver gene expression, resulting from CSH deficiency. We sought to examine the impact of CSH deficiency on fetal and placental size earlier in gestation (50 dGA), and to examine placental gene expression at 50 and $135 \mathrm{dGA}$. At $50 \mathrm{dGA}, \mathrm{CSH}$-deficient pregnancies exhibited a $41 \%$ reduction $(P \leq 0.05)$ in uterine vein concentrations of $\mathrm{CSH}$, and significant $(P \leq 0.05)$ reductions $(\approx 21 \%)$ in both fetal body and liver weights. Placentae harvested at 50 and $135 \mathrm{dGA}$ exhibited reductions in IGF1 and IGF2 mRNA concentrations, along with reductions in SLC2A1 and SLC2A3 mRNA. By contrast, mRNA concentrations for various members of the System A, System $\mathrm{L}$ and System $\mathrm{y}^{+}$amino acid transporter families were not significantly impacted. The IUGR observed at the end of the first-third of gestation indicates that the near-term IUGR reported previously, began early in gestation, and may have in part resulted from deficits in the paracrine action of CSH within the placenta. These results provide further compelling evidence for the importance of $\mathrm{CSH}$ in the progression and outcome of pregnancy.

$\begin{aligned} & \text { Key Words } \\ & \text { chorionic } \\ & \text { somatomammotropin } \\ - & \text { placental lactogen } \\ - & \text { sheep } \\ - & \text { placenta } \\ - & \text { lentivirus } \\ - & \text { RNA interference } \\ - & \text { SLC2A1 } \\ - & \text { SLC2A3 }\end{aligned}$

Journal of Endocrinology (2018) 237, 301-310

\section{Introduction}

Various complications during pregnancy can impact the health and survival of a fetus, among the most significant of these being intrauterine growth restriction (IUGR). IUGR affects upwards to $8 \%$ of human pregnancies, and occurs when a fetus fails to grow to its full potential (Gagnon 2003). IUGR is a leading cause of perinatal mortality and is associated with an increased risk of adult-onset disease such as hypertension, heart disease, diabetes and stroke (Barker \& Osmond 1986, Barker et al. 1989, 1990, 1993a,b,
Gagnon 2003). Functional placental insufficiency accounts for at least half of IUGR cases when the fetus is normally formed (Ghidini 1996). As the placenta mediates the exchange of nutrients and oxygen from the mother to the fetus (Barry \& Anthony 2008), placental insufficiency results in relative fetal undernutrition, impairing normal growth and development. Furthermore, the placenta is itself a highly metabolic organ, metabolizing a majority of the glucose and oxygen delivered to it (Meschia et al. 1980, 
Bell et al. 1986), as well as producing an array of hormones and growth factors that impact maternal and fetal metabolism and promote fetal growth and development. Of these, chorionic somatomammotropin ( $\mathrm{CSH}$, a.k.a. placental lactogen) has long been hypothesized to impact metabolism in both the mother and fetus (Handwerger 1991, Handwerger \& Freemark 2000).

CSH is a member of the growth hormone/prolactin gene family that is synthesized and secreted by syncytiotrophoblasts in the human placenta and binucleate cells in the sheep placenta (Gootwine 2004). Both human and sheep IUGR pregnancies are associated with reduced concentrations of CSH in maternal circulation (Spellacy 1976, Lea et al. 2008), and CSH is among the most abundantly produced placental proteins, continuously secreted into maternal and fetal circulation throughout pregnancy (Walker et al. 1991, Wooding \& Burton 2008). However, until recently (Baker et al. 2016), there was no direct evidence as to whether CSH deficiency had a causative, correlative or dependent relationship with IUGR. Baker et al. (2016) reported the generation of CSH-deficient sheep pregnancies, generated by lentiviral-mediated RNA interference in vivo, which resulted in significant IUGR near-term.

At 135 days of gestation (dGA), CSH-deficient pregnancies (Baker et al. 2016) exhibited 52\% and 32\% reductions in placental and fetal weights, respectively, as a result of $50 \%$ and $38 \%$ reductions in CSH mRNA and protein. The observed growth restriction was associated with significant reductions in umbilical concentrations of insulin and insulin-like growth factor 1 (IGF1), as well as fetal hepatic concentrations of IGF1, IGF2, IGFBP2 and IGFBP3 mRNA, supporting hypotheses about $\mathrm{CSH}$ actions within the fetus (Handwerger 1991, Handwerger \& Freemark 2000). However, maternal concentrations of insulin and IGF1, as well as maternal hepatic concentrations of IGF1, IGF2 and IGFBP mRNA, were not impacted by CSH deficiency, contrary to what had been previously hypothesized about the actions of CSH on maternal physiology (Handwerger 1991, Handwerger \& Freemark 2000). To determine whether CSH deficiency impacted placental and fetal growth prior to late gestation, we generated additional pregnancies, which were harvested at the end of the first-third of gestation (50 dGA), and utilized the resulting tissue, as well as tissue harvested at 135 dGA (Baker et al. 2016), to investigate the impact of CSH deficiency on placental expression of the IGFs, glucose and amino acid transporters. It was our hypothesis that CSH deficiency impacts placental growth during early- to mid-gestation, setting the stage for fetal growth restriction during late gestation.

\section{Materials and methods}

All procedures conducted with animals and lentivirus were approved by the Colorado State University Institutional Animal Care and Use Committee (Protocol 14-5257A) and the Institutional Biosafety Committee (Protocols 11-034B and 13-043B), respectively.

\section{Lentivirus generation}

Generation of hLL3.7 tg6, which expresses an shRNA targeting CSH mRNA, was previously described (Baker et al. 2016). The scrambled control sequence used by Baker et al. (2016) was cloned into LL3.7, using the same procedures as described for hLL3.7 $\operatorname{tg} 6$, thereby generating hLL3.7 NTS (non-targeting sequence/scrambled control). The shRNA sequences for both hLL3.7 tg6 and hLL3.7 NTS are presented in Table 1. Generation and titering of virus harboring the hLL3.7 tg6 and hLL3.7 NTS constructs followed the procedures extensively described by Baker et al. (2016).

\section{Blastocyst collection and transfer}

Individual hatched and fully expanded blastocysts, harvested from donor ewes 9 days after breeding, were infected with 100,000 transducing units of either hLL3.7 NTS or hLL3.7 tg6, as previously described (Baker et al. 2016). Following $\approx 5 \mathrm{~h}$ of incubation with the virus, the blastocysts were thoroughly washed in HCDM-2 media (Baker et al. 2016) and a single blastocyst was surgically transferred to each synchronized recipient ewe. Recipient ewes were monitored for return to standing estrus daily. The recipient ewes were group housed and fed to meet, or slightly exceed, their gestational nutrient requirements.

\section{Tissue collection}

At 50 dGA, 8 hLL3.7 NTS pregnancies (control) and 6 hLL3.7 tg6 pregnancies (CSH-deficient) were harvested at terminal surgery as previously described (Baker et al. 2016). Uterine vein blood was harvested prior to euthanization of the ewe and fetus $(90 \mathrm{mg} / \mathrm{kg}$ sodium pentobarbital; intravenous infusion of the uterine vein and umbilical vein), and the resulting serum was stored at $-80^{\circ} \mathrm{C}$, before being assayed for CSH concentrations (Kappes et al. 1992, Lea et al. 2008, Baker et al. 2016). Fetal body weight (FBW) and crown-rump length (CRL) were recorded for each fetus. Fetal livers were harvested, recorded for weight and stored in $50-\mathrm{mL}$ conical tubes snap-frozen 
Table 1 Scrambled control and CSH-targeting shRNA sequences.

\begin{tabular}{l}
\hline Oligonucleotide \\
\hline NTS shRNA sense \\
tg6 shRNA sense
\end{tabular}

Sequence $\left(5^{\prime}-3^{\prime}\right)$

GAGTTAAAGGTTCGGCACGAATTCAAGAGATTCGTGCCGAACCTTTAACTC AAGGCCAAAGTACTTGTAGACTTCAAGAGAGTCTACAAGTACTTTGGCCTT in liquid nitrogen. After hysterectomies were performed, all placentomes (combination of maternal caruncle and fetal cotyledon) were excised, washed in PBS and recorded for placental weight (PW) and total placentome number. The fetal cotyledons were separated from the maternal caruncles, and the fetal cotyledons were snap-frozen in liquid nitrogen, before being pulverized using a mortar and pestle. Pulverized tissue was kept frozen at $-80^{\circ} \mathrm{C}$ for later use. Harvest of placental tissue (fetal cotyledon) from control and CSH-deficient pregnancies at $135 \mathrm{dGA}$, as well as the characteristics of those pregnancies, has been previously reported (Baker et al. 2016).

\section{RNA isolation}

Total cellular RNA was isolated from 50 dGA fetal placenta and liver, as well as from 135 dGA fetal placenta (Baker et al. 2016) using the RNeasy Mini Kit (Qiagen) according to the manufacturer's protocol. The BioTek Synergy 2 Microplate Reader (BioTek) was used to quantify RNA concentration, and measure RNA purity using the 260/280 absorbance ratio. Samples were stored at $-80^{\circ} \mathrm{C}$ until use.

\section{cDNA synthesis and quantitative real-time PCR}

cDNA was generated from $1 \mu \mathrm{g}$ of total cellular RNA using iScript Reverse Transcription Supermix (Bio-Rad) according to the manufacturer's protocol. All cDNA samples were treated with 5 units of RNase H (Thermo Fisher Scientific) at $37^{\circ} \mathrm{C}$ for $20 \mathrm{~min}$. To control for variance in efficiency of the reverse transcription reaction, cDNA was quantified using the Quant-iT OliGreen ssDNA Assay Kit (Invitrogen) according to the manufacturer's protocol. An equal mass of cDNA (20 ng) was used for each sample in the quantitative real-time PCR (qPCR) reaction.

qPCR was performed using the LightCycler 480 (Roche Applied Science) and protocol previously described (Baker et al. 2016). Forward and reverse primers for qPCR were designed using Oligo software (Molecular Biology Insights, Cascade, CO, USA) to amplify an intronspanning product. Primer sequences and amplicon sizes are summarized in Table 2. A PCR product for each gene was generated using cDNA from 135 dGA fetal placenta as a template and cloned into the StrataClone vector (Agilent Technologies). Amplification of the correct cDNA was verified by sequencing each PCR product (Colorado State University Proteomics and Metabolomics Facility). Standard curves were generated for each mRNA from $1 \times 10^{2}$ to $1 \times 10^{-5} \mathrm{pg}$ using the PCR products amplified from the sequenced plasmids and were used to measure amplification efficiency. Starting quantities (pg) were normalized by dividing the starting quantity of the mRNA of interest by the starting mRNA quantity (pg) of ovine ribosomal S15 (RPS15). All primers were annealed at $60^{\circ} \mathrm{C}$. The starting quantity (pg) of RPS15 mRNA was not impacted $(P \geq 0.25)$ by CSH deficiency in either 50 or 135 dGA tissues.

\section{Western immunoblotting}

Cellular protein from 50 and 135 dGA fetal placenta (cotyledon) tissue was assessed using Western immunoblot analysis. To isolate total cellular protein, cotyledon tissue $(100 \mathrm{mg})$ was lysed in $500 \mu \mathrm{L}$ of Western lysis buffer $(0.48 \mathrm{M}$ Tris, $\mathrm{pH} 7.4 ; 10 \mathrm{mM}$ EGTA, pH 8.6; $10 \mathrm{mM}$ EDTA, pH 8; $0.1 \mathrm{mM}$ PMSF; $0.1 \mathrm{mM}$ AEBSF; $0.0015 \mathrm{mM}$ pepstatin A; $0.0014 \mathrm{mM}$ E-64; $0.004 \mathrm{mM}$ bestatin; $\quad 0.002 \mathrm{mM}$ leupeptin; and $0.00008 \mathrm{mM}$ aprotinin) and sonicated on ice. $10-50 \mu \mathrm{g}$ of protein from each sample was electrophoresed through a $4-12 \%$ BisTris gel (Life Technologies) and transferred to a $0.45-\mu \mathrm{m}$ pore nitrocellulose membrane. To visualize CSH $(1: 25,000$ dilution, $\alpha$-oPL-S4; Kappes et al. 1992), SLC2A1 (1:2000 dilution, product no. 07-1401; EMD Millipore) and SLC2A3 (1:500 dilution, product no. ab125465; Abcam), an antirabbit horseradish peroxidase-conjugated IgG (1:5000 dilution, product no. sc-2004; Santa Cruz Biotechnology) was used. As a loading control and housekeeping protein to normalize CSH, SLC2A1 and SLC2A3, a polyclonal antibody to $\beta$-actin (ACTB, 1:2500 dilution, product no. sc-47778; Santa Cruz Biotechnology) bound by a horseradish peroxidase-conjugated secondary antibody (1:5000, product no. sc-2005; Santa Cruz Biotechnology) was used. Membranes were developed using an ECL Western Blotting Detection Reagent chemiluminescent kit (Amersham) and imaged using the ChemiDoc XRS ${ }^{+}$ chemiluminescence system (Bio-Rad). Densitometry calculations were performed using Image Lab Software (Bio-Rad). Technical error between membranes was corrected by including a common sample in each Western 
Table 2 Primers and product sizes for CDNA used in qPCR.

\begin{tabular}{l}
\hline CDNA \\
\hline IGF1 \\
IGF2 \\
IGFBP1 \\
IGFBP2 \\
IGFBP3 \\
RPS15 \\
SLC2A1 \\
SLC2A3 \\
SLC38A1 \\
SLC38A2 \\
SLC38A4 \\
SLC7A5 \\
SLC7A8 \\
SLC7A1
\end{tabular}

Forward primer
TCG CAT CTC TTC TAT CTG GCC CTG T
GAC CGC GGC TTC TAC TTC AG
TGA TGA CCG AGT CCA GTG AG
CAA TGG CGA GGA GCA CTC TG
CTC AGA GCA CAG ACA CCC A
ATC ATT CTG CCC GAG ATG GTG
GAC AGG GAG GAG CAA GCC AAA
CTC TAC TGC TGG GCT TCA CC
CCC GAA GAC GAT AAC ATT AGC AA
CTT GCT GCC CTC TTT GGA T
CTA TTC GCA CAT CAG TGA C
GCT CGG CTT CAT CCA GAT C
TAT TGC TCC TCA CAT GGG TCA
CTT ACG GTA TCA GCC CGA GCA

\begin{tabular}{lcc} 
Reverse primer & Product (bp) \\
\cline { 1 - 2 } ACA GTA CAT CTC CAG CCT CCT CAG A & 240 \\
AAG AAC TTG CCC ACG GGG TAT & 203 \\
GTC CAG CGA AGT CTC ACA C & 248 \\
TGG GGA TGT GTA GGG AAT AG & 330 \\
GGC ATA TTT GAG CTC CAC & 336 \\
TGC TTG ACG GGC TTG TAG GTG & 134 \\
TAG GGT GAA GCC AGG GAT GTG & 380 \\
ACT TGC TTC TCC TGC GAC AT & 211 \\
CTC CCA GCT TTT CAT AAA CCA & 382 \\
CAA CAC AGC CAA ACG GAC AA & 120 \\
TGA AAA TGA TGC CAA CCA C & 279 \\
AGG CAA AGA GGC CGC TGT A & 122 \\
GAC AAG CTC CTC AGT CAC GTA & 272 \\
GAA AGA CTG CTG CCC ACA ACT CCC & 320
\end{tabular}

immunoblot. Densitometry measurements were adjusted were significantly $(P \leq 0.01)$ reduced in the 50 dGA based on the average densitometry measurement of the common sample and normalized to ACTB.

\section{Statistical analyses}

All data were subjected to analysis of variance using SAS software (SAS Institute, Cary, NC, USA) and the PROC Mixed procedure, with treatment and fetal sex as dependent variables and the treatment $\times$ fetal sex interaction. There was not a significant fetal sex effect (50 dGA), or a significant treatment by fetal sex interaction; subsequently data from control and CSHdeficient pregnancies were compared by Student's $t$-test within a gestational age. Statistical significance was set at $P \leq 0.05$, and statistical tendency was set at $P \leq 0.10$. Data are reported as the mean \pm S.E.M.

\section{Results}

\section{Day 50 fetal and placental measurements}

Following viral infection and single blastocyst transfer, 8 control (50\% males) and 6 CSH-deficient (33\% males) pregnancies were harvested at 50 dGA. FBW, CRL, fetal liver weight (FLW) and PW are presented in Table 3. As evidenced in Table 3, both FBW and FLW CSH-deficient pregnancies, whereas CRL and PW only tended $(P \leq 0.10)$ to be impacted. Placental efficiency (FBW/PW) was not impacted $(P \geq 0.10)$ by CSH deficiency (Table 3). Uterine vein CSH concentrations were reduced $(P \leq 0.05) \approx 41 \%$ in $\mathrm{CSH}$-deficient pregnancies (Fig. 1$)$, as compared to control pregnancies. $\mathrm{CSH}$ mRNA and protein concentrations within the placenta were both reduced $\approx 21 \%$ in CSH-deficient pregnancies, but these differences were not statistically significant (Fig. 1).

\section{Insulin-like growth factor and insulin-like growth factor binding proteins}

At $50 \mathrm{dGA}$, there were no statistical differences in mRNA concentrations for IGF1, IGF2, or any of the three IGFBPs (Table 4) within the fetal liver. Within the placenta, IGF1 mRNA concentrations were reduced at $50(P=0.12)$ and $135(P \leq 0.05)$ dGA (Table 5$)$, whereas IGF2 mRNA concentration was reduced $(P \leq 0.05)$ only at $135 \mathrm{dGA}$. Placental expression of IGFBP 1 was undetectable at $50 \mathrm{dGA}$ (Table 5), whereas at $135 \mathrm{dGA}$, there was a tendency $(P=0.11)$ for increased IGFBP1 mRNA concentration in $\mathrm{CSH}$-deficient pregnancies relative to control pregnancies. By contrast, IGFBP2 mRNA concentration was reduced $(P \leq 0.05)$ at $50 \mathrm{dGA}$ in CSH-deficient pregnancies, but there was no treatment effect at $135 \mathrm{dGA}$ (Table 5).

Table 3 Fetal and placental measurements for 50 dGA pregnancies.

\begin{tabular}{lc}
\hline $\mathbf{5 0}$ dGA & Controls \\
\hline Fetal weight (g) & $17.17 \pm 0.39$ \\
CRL (cm) & $9.5 \pm 0.11$ \\
Fetal liver (g) & $1.32 \pm 0.06$ \\
Placenta weight (g) & $105.5 \pm 4.42$ \\
Placental efficiency (g/g) & $0.165 \pm 0.008$ \\
\hline & \\
\hline http://joe.endocrinology-journals.org & C 2018 Society for Endocrinology \\
https://doi.org/10.1530/JOE-18-0093 & Published by Bioscientifica Ltd. \\
\multicolumn{2}{l}{ Printed in Great Britain }
\end{tabular}

\begin{tabular}{c}
\hline CSH-deficient \\
$13.65 \pm 0.61$ \\
$8.5 \pm 0.20$ \\
$1.04 \pm 0.08$ \\
$88.1 \pm 10.31$ \\
$0.165 \pm 0.02$
\end{tabular}

\begin{tabular}{c} 
P value \\
\hline 0.01 \\
0.10 \\
0.01 \\
0.11 \\
0.98
\end{tabular}

\begin{tabular}{c}
\hline \% difference \\
\hline 20.5 \\
10.4 \\
20.9 \\
16.5 \\
0.32 \\
\hline
\end{tabular}



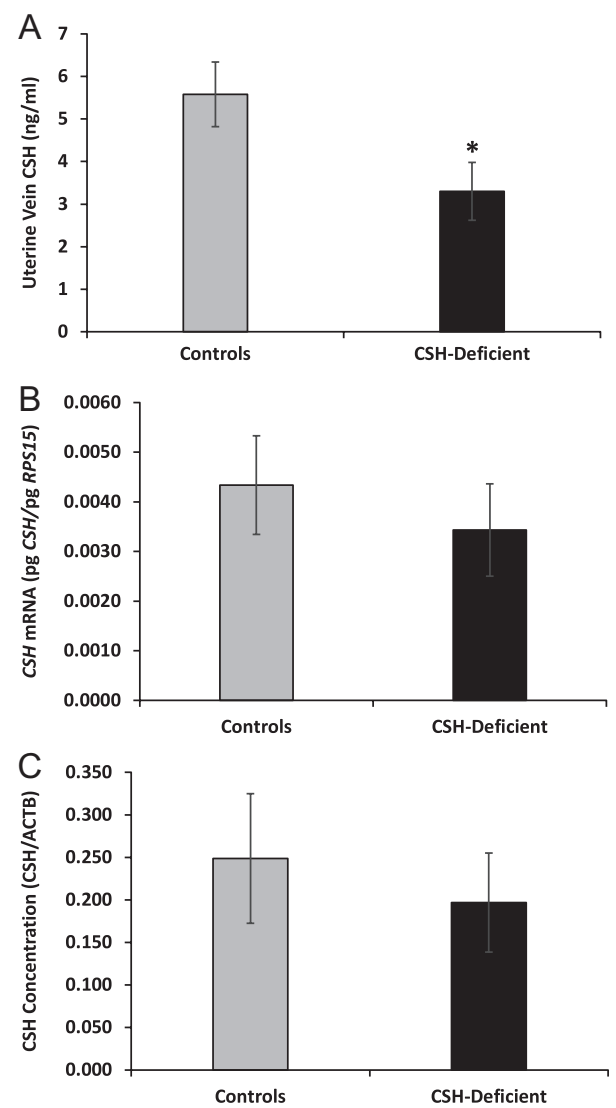

Figure 1

(A) Uterine vein CSH concentration at $50 \mathrm{dGA}$. (B) Placental CSH mRNA concentrations at $50 \mathrm{dGA}$. (C) Placental CSH concentrations at $50 \mathrm{dGA}$. $* P \leq 0.05$ when $\mathrm{CSH}$-deficient pregnancies are compared with controls.

Placental IGFBP3 mRNA concentration was not statistically impacted by treatment at either 50 or 135 dGA.

\section{Nutrient transporters}

As evidenced in Fig. 2, SLC2A1 mRNA concentration was reduced $(P \leq 0.05)$ in $\mathrm{CSH}$-deficient placenta at 50 and $135 \mathrm{dGA}$, relative to controls. However, placental SLC2A1 concentration (Fig. 2) was not statistically reduced at either 50 or 135 dGA. By contrast SLC2A3 mRNA (Fig. 3) was reduced only by $24 \%(P \geq 0.10)$ at $50 \mathrm{dGA}$, but was significantly less $(49 \% ; P \leq 0.05)$ in $\mathrm{CSH}$-deficient placenta at 135 dGA. Placental SLC2A3 concentration (Fig. 3) mirrored the changes in mRNA concentrations, with a nonsignificant $(P \geq 0.10) 17 \%$ reduction at $50 \mathrm{dGA}$, and a significant $32 \%$ reduction $(P \leq 0.05)$ at $135 \mathrm{dGA}$ in CSH-deficient pregnancies. There was no effect of $\mathrm{CSH}$ deficiency at 50 dGA on SLC2A 8 mRNA concentration (Fig. 4), but $S L C 2 A 8$ mRNA was increased $(P \leq 0.05)$ in $\mathrm{CSH}$ deficient placenta at $135 \mathrm{dGA}$ (Fig. 4). We were unable to identify an antiserum that allowed the specific assessment of sheep SLC2A8 by Western immunoblot analysis.

The mRNA concentration of System A (SLC38A1, SLC38A2 and SLC38A4), System L (SLC7A5 and SLC7A8) and System $\mathrm{y}^{+}(S L C 7 A 1)$ amino acid transporter families was assessed in our control and CSH-deficient pregnancies harvested at 50 and 135 dGA. As evidenced in Fig. 5, there were no significant changes in the mRNA concentration of any of these amino acid transporters at $50 \mathrm{dGA}$, as a result of $\mathrm{CSH}$ deficiency. At 135 dGA (Fig. 5), the only transporter that appeared to be impacted by $\mathrm{CSH}$ deficiency was SLC38A4 (SNAT4), which tended $(P \leq 0.10)$ to be reduced.

\section{Discussion}

Using lentiviral-mediated RNA interference, we recently reported the generation of $\mathrm{CSH}$-deficient pregnancies in sheep (Baker et al. 2016). Near-term (135 dGA), CSHdeficient pregnancies (Baker et al. 2016) were characterized by significant fetal (32\% reduction) and placental (52\% reduction) growth restriction, associated with reductions in placental CSH mRNA (50\%) and protein (38\%). These results provided support for the long-held hypothesis that CSH promotes fetal growth (Handwerger 1991, Handwerger \& Freemark 2000). The purpose of the current study was to determine whether CSH deficiency manifested changes in placental function and fetal growth at the end of the first-third of gestation (50 dGA), a time point when the placenta is fully established and continuing to grow.

At the end of the first-third of gestation, we observed significant $(P \leq 0.01)$ reductions in fetal weight and FLWs, suggesting that the growth restriction observed near-term

Table 450 dGA fetal liver insulin-like growth factor mRNA concentrations.

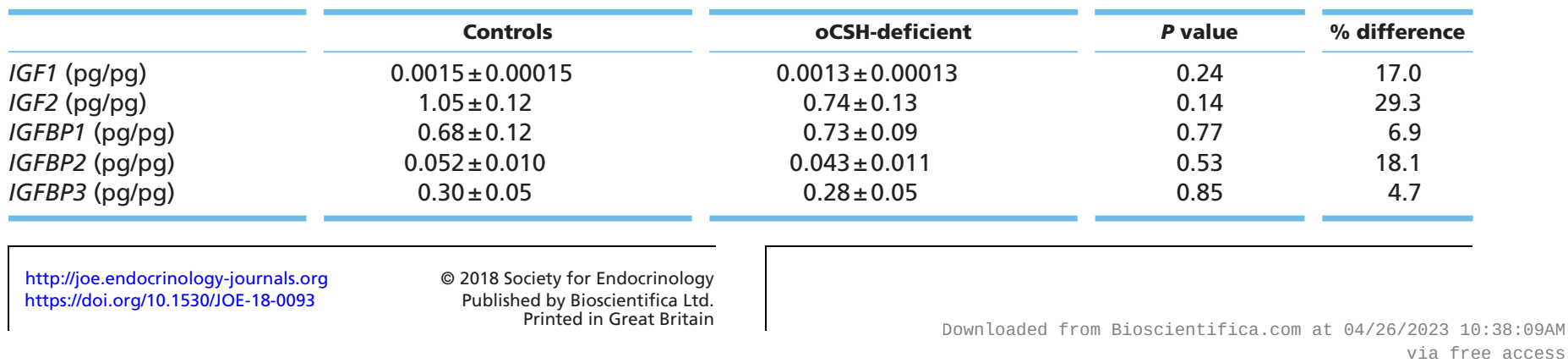


Table 550 and 135 dGA placenta insulin-like growth factor mRNA concentrations.

\begin{tabular}{cc}
\hline & Controls \\
\hline $50(\mathrm{dGA})$ & $0.000081 \pm 0.000028$ \\
IGF1 $(\mathrm{pg} / \mathrm{pg})$ & $0.082 \pm 0.012$ \\
IGF2 $(\mathrm{pg} / \mathrm{pg})$ & 0 \\
IGFBP1 & $0.0022 \pm 0.00060$ \\
IGFBP2 $(\mathrm{pg} / \mathrm{pg})$ & $0.026 \pm 0.006$ \\
IGFBP3 $(\mathrm{pg} / \mathrm{pg})$ & $0.003 \pm 0.0009$ \\
$135(\mathrm{dGA})$ & $0.36 \pm 0.07$ \\
IGF1 $(\mathrm{pg} / \mathrm{pg})$ & $0.00021 \pm 0.00007$ \\
IGF2 $(\mathrm{pg} / \mathrm{pg})$ & $0.0024 \pm 0.0006$ \\
IGFBP1 & $0.047 \pm 0.008$ \\
IGFBP2 $(\mathrm{pg} / \mathrm{pg})$ & \\
IGFBP3 $(\mathrm{pg} / \mathrm{pg})$ & \\
\hline
\end{tabular}

(Baker et al. 2016) in CSH-deficient pregnancies started during early gestation. Although PW only tended to be smaller at 50 dGA (Table 3), the ratio of fetal weight to PW (i.e., placental efficiency) was equivalent between control and CSH-deficient pregnancies. This would suggest that placental size/function was the driving force behind the fetal growth restriction observed at $50 \mathrm{dGA}$.

In contrast to what we observed (Baker et al. 2016) near-term, there was a significant $(P \leq 0.05)$ reduction in uterine vein concentrations of $\mathrm{CSH}$. At $50 \mathrm{dGA}$, due to the size of the fetus and amount of fetal blood, we could not harvest sufficient umbilical blood to assess CSH concentrations, as we did at 135 dGA (Baker et al. 2016). As discussed in Baker et al. (2016), blood concentrations of CSH become quite variable toward the end of gestation (Taylor et al. 1980, Butler et al. 1987, Bauer et al. 1995), and surgery elevates both maternal and fetal concentrations of CSH for up to 5 days (Taylor et al. 1980). Similar studies of CSH variability over time, during early to mid-gestation, have not been reported. However, simply comparing the overall (both control and CSH-deficient) coefficients of variation for the uterine vein values obtained at $50 \mathrm{dGA}$ ( $\approx 16 \%)$ vs 135 dGA ( $\approx 1858 \%)$ infers that CSH secretion into maternal circulation is not nearly as variable during early to mid-gestation as it is near-term. Maternal and fetal vascular cannulation and harvest of serial samples obtained undernon-stressed/non-anesthetized conditions, along with blood flow measurements, will be necessary to accurately assess the impact of CSH RNA interference on maternal and fetal concentrations of $\mathrm{CSH}$. To our surprise, within the CSH-deficient placenta at $50 \mathrm{dGA}$, we could not demonstrate a statistically significant change in CSH mRNA and protein, as we had at 135 dGA. Unfortunately, we cannot fully explain discrepancies between these two studies as a result of in vivo RNA interference on placental CSH mRNA and protein. This could result from day-to-day variability in shRNA expression and function, but to our Printed in Great Britain

\begin{tabular}{|c|c|c|}
\hline CSH-deficient & $P$ value & $\%$ difference \\
\hline $0.000024 \pm 0.000008$ & 0.12 & 69.6 \\
\hline $0.064 \pm 0.009$ & 0.28 & 21.4 \\
\hline \multicolumn{3}{|l|}{0} \\
\hline $0.0006 \pm 0.00025$ & 0.04 & 73.1 \\
\hline $0.019 \pm 0.004$ & 0.41 & 27.3 \\
\hline $0.001 \pm 0.0002$ & 0.03 & 65.7 \\
\hline $0.17 \pm 0.05$ & 0.04 & 53.3 \\
\hline $0.00057 \pm 0.00019$ & 0.11 & 62.5 \\
\hline $0.0029 \pm 0.0010$ & 0.69 & 16.8 \\
\hline $0.045 \pm 0.007$ & 0.88 & 3.4 \\
\hline
\end{tabular}

knowledge, there is no approach to directly address this potential variability in vivo.

In contrast to the robust reduction in fetal liver mRNA concentrations for IGF1, IGF2, IGFBP2 and IGFBP3 observed at $135 \mathrm{dGA}$ (Baker et al. 2016), at $50 \mathrm{dGA}$, neither IGF1 and IGF2 mRNA concentration were significantly changed, nor were fetal liver mRNA concentrations for all three IGFBPs impacted by CSH deficiency. Due to the major impact of CSH deficiency on placental size observed
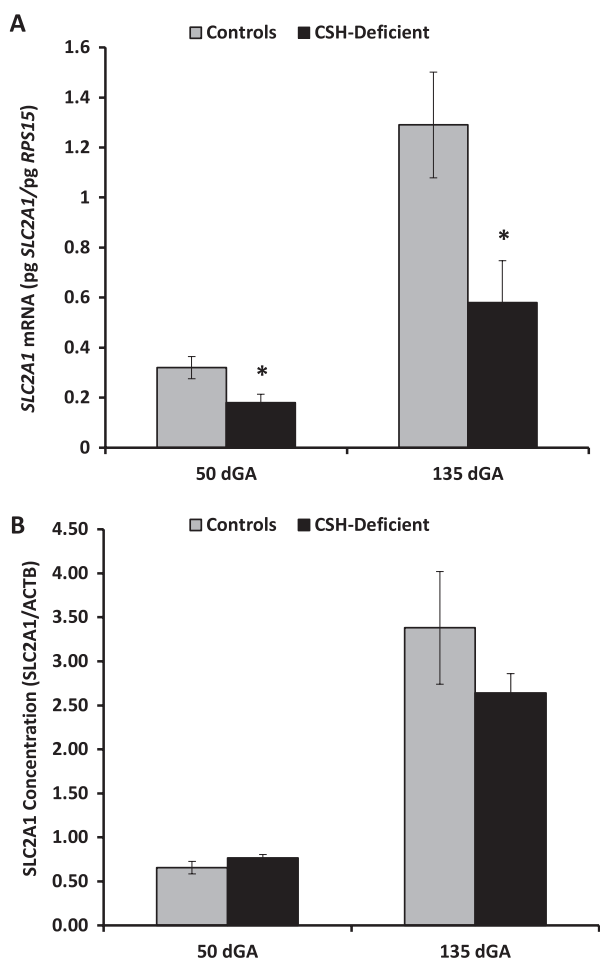

Figure 2

(A) Effect of CSH deficiency on SLC2A1 mRNA concentrations in the placenta at 50 and 135 dGA. (B) Effect of CSH deficiency on SLC2A1 concentrations in the placenta at 50 and $135 \mathrm{dGA}$. ${ }^{*} P \leq 0.05$ when $\mathrm{CSH}$-deficient pregnancies are compared with controls, within a gestational age. 


\begin{tabular}{l|l|l|c|c|}
\hline Journal of & K M Jeckel et al. & Impact of CSH deficiency & $\mathbf{2 3 7 : 3}$ \\
Endocrinology & & $\mathbf{3 0 7}$
\end{tabular}
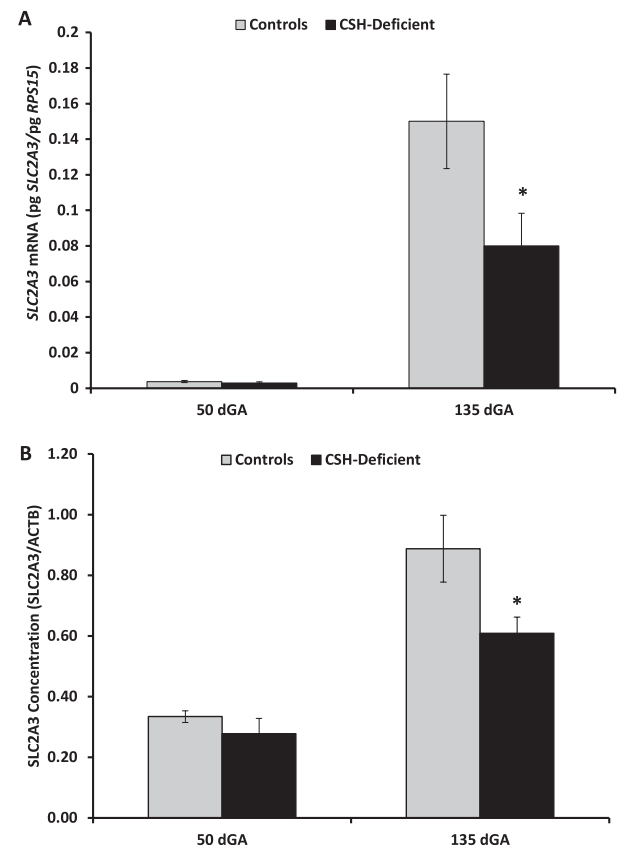

Figure 3

(A) Effect of CSH deficiency on SLC2A3 mRNA concentrations in the placenta at 50 and $135 \mathrm{dGA}$. (B) Effect of CSH deficiency on SLC2A3 concentrations in the placenta at 50 and $135 \mathrm{dGA}$. ${ }^{*} \leq 0.05$ when $\mathrm{CSH}$-deficient pregnancies are compared with controls, within a gestational age.

at 135 dGA (Baker et al. 2016), we reasoned that at least part of CSH's impact may result from paracrine actions within the placenta. Accordingly, we examined the mRNA concentrations of IGF1, IGF2, IGFBP1, IGFBP2 and IGFBP3 in the placenta harvested at both 50 and 135 dGA (Baker et al. 2016). At $50 \mathrm{dGA}$, placental IGF1 tended (Table 5) to be reduced, and $I G F B P 2$ was significantly lower, whereas $I G F 2$, IGFBP1 and IGFBP3 were not impacted. However, near-term (135 dGA) placental concentrations of IGF1 and IGF2 mRNA were both significantly reduced, as they were in the near-term fetal liver (Baker et al. 2016). In contrast to what was observed in the near-term fetal liver

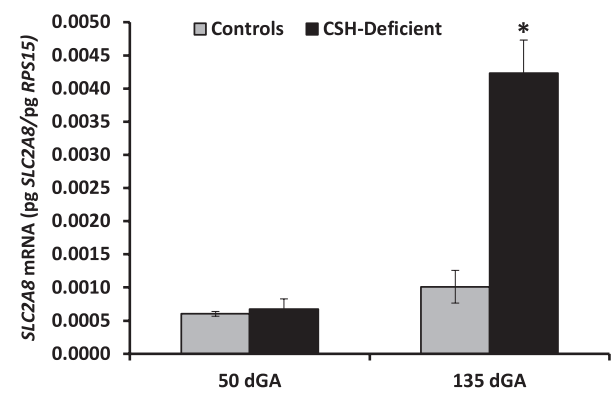

Figure 4

Effect of CSH deficiency on SLC2A8 mRNA concentrations in the placenta at 50 and $135 \mathrm{dGA}$. ${ }^{*} P \leq 0.05$ when $\mathrm{CSH}$-deficient pregnancies are compared with controls, within a gestational age.

(C) 2018 Society for Endocrinology Published by Bioscientifica Ltd. Printed in Great Britain
(Baker et al. 2016), neither IGFBP2 nor IGFBP3 mRNA concentration was impacted by placental CSH deficiency at $135 \mathrm{dGA}$. While it is difficult to draw firm conclusions from these samples, the disparity in expression of the various IGF axis components between the placenta and fetal liver, and between the two gestational ages examined, may result from both direct effects (i.e., directly within the placenta or fetus) and indirect effects (i.e., placental mediated effects on the fetus) of CSH.

Due to the impact of CSH deficiency on placental IGF expression, and evidence that IGF can impact the expression of placental nutrient transporters (Wali et al. 2012, Jones et al. 2013, 2014, Baumann et al. 2014), we turned our attention to the expression of glucose and amino acid transporters within CSH-deficient placentae. Fitting with the hypothesis that CSH drives placental IGF1 expression and IGF1 in turn enhances SLC2A1 expression (Baumann et al. 2014), we observed diminished $(P \leq 0.05)$ expression of SLC2A1 mRNA at both $50 \mathrm{dGA}$ and $135 \mathrm{dGA}$,
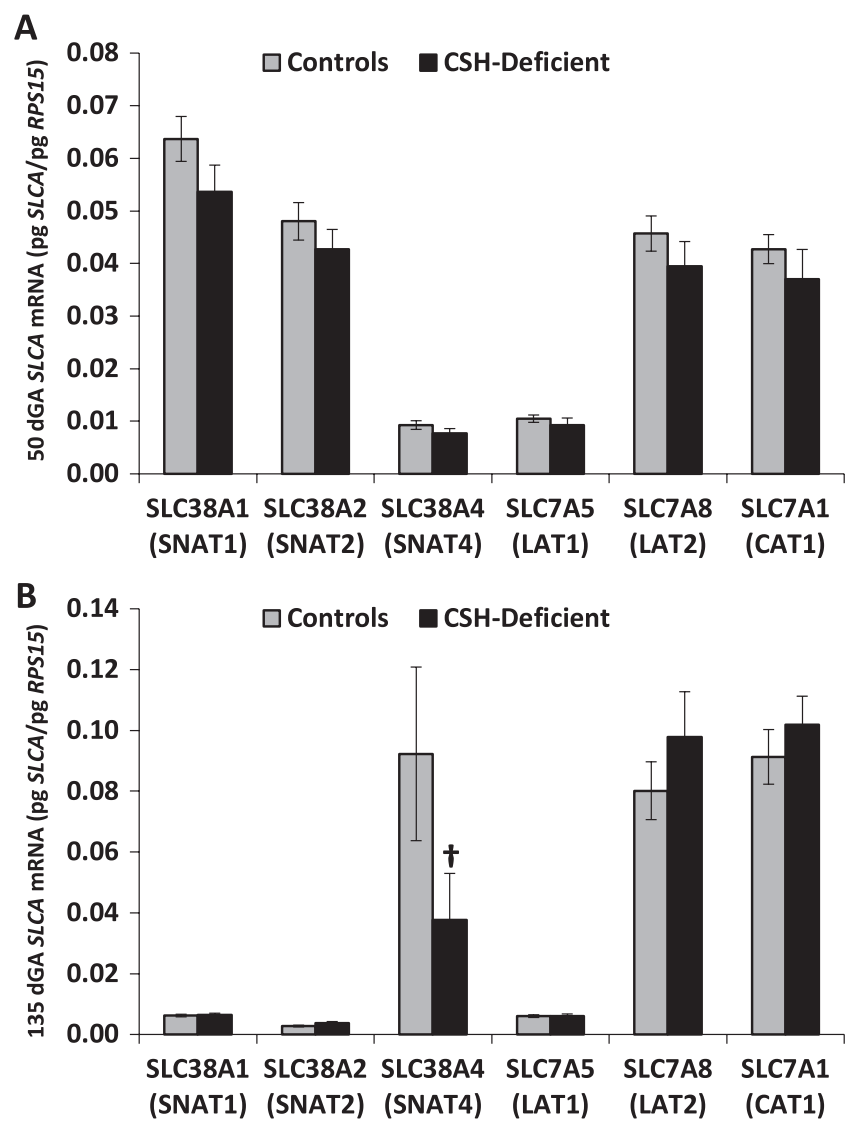

Figure 5

(A) Effect of CSH deficiency on amino acid transporter mRNA concentrations in the placenta at 50 dGA. (B) Effect of CSH deficiency on amino acid transporter mRNA concentrations in the placenta at $135 \mathrm{dGA}$. ${ }^{\dagger} P \leq 0.10$ when $\mathrm{CSH}$-deficient pregnancies are compared with controls, within a gestational age. 
whereas $S L C 2 A 3$ mRNA was significantly reduced $(P \leq 0.05)$ only at $135 \mathrm{dGA}$. In contrast to what was observed with the reductions in SLC2A1 mRNA, Western blot analysis of fetal placental homogenates revealed no significant change in SLC2A1 at either 50 or 135 dGA. Janzen et al. (2013) reported a significant reduction in SLC2A1 mRNA within the basal plate region of human IUGR placenta, similar to what we observed in this study, with no change in the concentration of SLC2A1 protein. It is possible that $S L C 2 A 1$ is so highly expressed in the placenta that there is a functional 'reserve' of SLC2A1 mRNA, making SLC2A1 less susceptible to 'outside' influences.

In contrast to SLC2A1, there was a similar magnitude of change at both 50 and $135 \mathrm{dGA}$ for both SLC2A3 mRNA and protein. Similar to the human, SLC2A1 is much more abundant than SLC2A3 in the sheep placenta, but in sheep, SLC2A1 is located on the trophoblast basolateral surface, whereas SLC2A3 is located solely on the maternalfacing apical microvillous surface (Wooding et al. 2005). While the expression of $S L C 2 A 3$ increases significantly during the latter half of gestation (Ehrhardt \& Bell 1997), due to its location (Wooding et al. 2005), affinity and glucose transport capacity (Simpson et al. 2008), similar to the human (Brown et al. 2011), SLC2A3 may play a significant role during the first-half of gestation as well, by mediating the uptake of glucose into the trophoblast. Due to the greater impact of CSH deficiency on SLC2A3 protein, lack of SLC2A3 may have been a driving force behind the growth restriction observed.

At $50 \mathrm{dGA}$, there was no difference in $S L C 2 A 8 \mathrm{mRNA}$, but at $135 \mathrm{dGA}$, there was a $\approx 76 \%$ increase $(P \leq 0.05)$ in $S L C 2 A 8$ mRNA concentration. It has been reported that SLC2A8 placental mRNA and protein expression is decreased in the hyperthermic-model of sheep IUGR (Limesand et al. 2004). However, Wooding et al. (2005) was unable to identify significant membrane localization of SLC2A8 in any of the ruminant placenta examined. SLC2A8 is a class III glucose transporter (SLC2A1 and SLC2A3 are class I transporters; Joost et al. 2002), which is primarily localized to endosomes, lysosomes and endoplasmic reticulum membranes (Schmidt et al. 2009), and is thought to catalyze hexose transport across intracellular membranes. $S L C 2 A 8$ might be up-regulated in response to deficiencies in SLC2A1 or SLC2A3. If its role is as an intracellular transporter (Schmidt et al. 2009), its up-regulation may infer a mechanism by which the placenta preserves its metabolic function, which would fit with the reductions in mitochondrial membrane potential and ATP generation in sperm of Slc2A8-/- mice (Gawlik et al. 2008). While our data on $S L C 2 A 8$ are intriguing, since there is no evidence for its role in glucose transport to the fetus, its role in the resulting IUGR observed in CSH-deficient pregnancies at 50 and $135 \mathrm{dGA}$ is not readily apparent.

In contrast to the glucose transporters, we did not observe significant changes in mRNA concentrations for SLC38A1, SLC38A2, SLC38A4, SLC7A1, SLC7A5 or SLC7A8, except for a trend $(P \leq 0.10)$ for reduced $S L C 38 A 4$ (SNAT4) at 135 dGA. Placental transfer of amino acids, especially essential amino acids, is reduced in human and sheep IUGR pregnancies (Marconi et al. 1999, de Vrijer et al. 2004, Regnault et al. 2005). However, amino acid transporter mRNA and protein concentration is not a perfect surrogate for transporter activity in IUGR pregnancies (Mando et al. 2013, Chen et al. 2015, Dunlap et al. 2015, Pantham et al. 2016). Thorough in vivo assessment of placental uptake, net utilization and transfer to the fetus is required before any changes in placental nutrient transporter mRNA or protein concentrations can be interpreted completely.

Collectively, our current results, combined with the work of Baker et al. (2016), provide compelling evidence for the importance of CSH in the progression and outcome of pregnancy. Our initial study (Baker et al. 2016) supported the long-held hypotheses (Handwerger 1991, Handwerger \& Freemark 2000) that CSH promoted fetal growth by impacting fetal concentrations of IGF1 and insulin. Our current results expand the possible impact of $\mathrm{CSH}$ to actions within the placenta itself, including the expression of IGF1, IGFBP2 and glucose transporters. These paracrine actions within the placenta may have been responsible for the reduction in fetal growth that occurred during early gestation (50 dGA), but may have also set the stage for functional placental insufficiency during late gestation (135 dGA). Unfortunately, with both of our studies, it was not feasible to chronically catheterize the pregnancies, allowing steady-state investigations under non-stressed/ non-anesthetized conditions that will be required to determine direct effects of CSH within the placenta vs actions directly within the fetus. Regardless of these shortcomings, our results highlight the utility of in vivo lentiviral-mediated RNA interference to study the function of genes expressed by the placenta of large mammals. More importantly, they provide compelling evidence that $\mathrm{CSH}$ plays a critical role in the progression of pregnancy and lay the groundwork for future studies that can delineate the exact mechanisms by which CSH promotes fetal growth.

\section{Declaration of interest}

The authors declare that there is no conflict of interest that could be perceived as prejudicing the impartiality of the research reported. 


\section{Funding}

This work was supported by Agriculture and Food Research Initiative Competitive Grant no. 2012-67015-30215 from the USDA National Institute of Food and Agriculture (NIFA), USDA NIFA W3112 Multistate Project and NIH grant HD 090312.

\section{Acknowledgements}

The authors wish to thank Vince Abushaban, Richard Brandes, Zella Brink, Gregory Harding, Jay Kailey, Erin McWhorter and Rachel West for animal care and additional technical support.

\section{References}

Baker CM, Goetzmann LN, Cantlon JD, Jeckel KM, Winger QA \& Anthony RV 2016 The development of ovine chorionic somatomammotropin hormone deficent pregnancies. American Journal of Physiology: Regulatory, Integrative and Comparative Physiology 310 R837-R846. (https://doi.org/10.1152/ajpregu.00311)

Barker DJ \& Osmond C 1986 Infant mortality, childhood nutrition, and ischaemic heart disease in England and Wales. Lancet 327 1077-1081. (https://doi.org/10.1016/S0140-6736(86)91340-1)

Barker DJ, Osmond C, Golding J, Kuh D \& Wadsworth ME 1989 Growth in utero, blood pressure in childhood and adult life, and mortality from cardiovascular disease. BMJ 298 564-567. (https://doi. org/10.1136/bmj.298.6673.564)

Barker DJ, Bull AR, Osmond C \& Simmonds SJ 1990 Fetal and placental size and risk of hypertension in adult life. BMJ 301 259-262. (https:// doi.org/10.1136/bmj.301.6746.259)

Barker D, Godfrey K, Gluckman P, Harding J, Owens J \& Robinson J $1993 a$ Fetal nutrition and cardiovascular disease in adult life. Lancet 341 938-941. (https://doi.org/10.1016/0140-6736(93)91224-A)

Barker DJ, Hales CN, Fall CH, Osmond C, Phipps K \& Clark PM $1993 b$ Type 2 (non- insulin-dependent) diabetes mellitus, hypertension and hyperlipidaemia (syndrome $\mathrm{X}$ ): relation to reduced fetal growth. Diabetologia 36 62-67. (https://doi.org/10.1007/BF00399095)

Barry JS \& Anthony RV 2008 The pregnant sheep as a model for human pregnancy. Theriogenology 69 55-67. (https://doi.org/10.1016/j. theriogenology.2007.09.021)

Bauer MK, Breier BH, Harding JE, Veldhuis JD \& Gluckman P 1995 The fetal somatotropic axis during long term maternal undernutrition in sheep: evidence for nutritional regulation in utero. Endocrinology 136 1250-1257. (https://doi.org/10.1210/endo.136.3.7867579)

Baumann MU, Schneider H, Malek A, Palta V, Surbek DV, Sager R, Zamudio S \& Illsley NP 2014 Regulation of human trophoblast GLUT1 glucose transporter by insulin-like growth factor I (IGFI). PLOS ONE 9 e106037. (https://doi.org/10.1371/journal. pone.0106037)

Bell AW, Kennaugh JM, Battaglia FC, Makowski EL \& Meschia G 1986 Metabolic and circulatory studies of fetal lamb at midgestation. American Journal of Physiology: Endocrinology and Metabolism 250 E538-E544. (https://doi.org/10.1152/ajpendo.1986.250.5.E538)

Brown K, Heller DS, Zamudio S \& Illsley NP 2011 Glucose transporter 3 (GLUT3) protein expression in human placenta across gestation. Placenta 32 1041-1049. (https://doi.org/10.1016/j. placenta.2011.09.014)

Butler WR, Huyler SE, Grandis AS \& Handwerger S 1987 Failure of fasting and changes in plasma metabolites to affect spontaneous fluctuations in plasma concentrations of ovine placental lactogen. Journal of Endocrinology 114 391-397. (https://doi.org/10.1677/joe.0.1140391)

Chen YY, Rosario FJ, Shehab MA, Powell TL, Gupta MB \& Jansson T 2015 Increased ubiquitination and reduced plasma membrane trafficking of placental amino acid transporter SNAT-2 in human IUGR. Clinical Science 129 1131-1141. (https://doi.org/10.1042/CS20150511)

Dunlap KA, Brown JD, Keith AB \& Satterfield MC 2015 Factors controlling nutrient availability to the developing fetus in ruminants. Journal of Animal Science and Biotechnology 6 16. (https://doi. org/10.1186/s40104-015-0012-5)

Ehrhardt RA \& Bell AW 1997 Developmental increases in glucose transporter concentration in the sheep placenta. American Journal of Physiology: Regulatory, Integrative and Comparative Physiology $\mathbf{2 7 3}$ R1132-R1141. (https://doi.org/10.1152/ajpregu.1997.273.3.R1132)

Gagnon R 2003 Placental insufficiency and its consequences. European Journal of Obstetrics Gynecology Reproductive Biology 110 S99-S107. (https://doi.org/10.1016/S0301-2115(03)00179-9)

Gawlik V, Schmidt S, Scheepers A, Wennemuth G, Augustin R, Aumuller G, Moser M, Al-Hasani H, Kluge R, Joost HG, et al. 2008 Targeted disruption of Slc2a8 (GLUT8) reduces motility and mitochondrial potential of spermatozoa. Molecular Membrane Biology 25 224-235. (https://doi.org/10.1080/09687680701855405)

Ghidini A 1996 Idiopathic fetal growth restriction. Obstetrical and Gynecological Survey 51 376-382.

Gootwine E 2004 Placental hormones and fetal-placental development. Animal Reproduction Science 82-83 551-566. (https://doi. org/10.1016/j.anireprosci.2004.04.008)

Handwerger S 1991 Clinical counterpoint: the physiology of placental lactogen in human pregnancy. Endocrine Reviews 12 329-336. (https:// doi.org/10.1210/edrv-12-4-329)

Handwerger S \& Freemark M 2000 The roles of placental growth hormone and placental lactogen in the regulation of human fetal growth and development. Journal of Pediatric Endocrinology and Metabolism 13 343-356.

Janzen C, Lei MYY, Cho J, Sullivan P, Shin B-C \& Devaskar SU 2013 Placental glucose transporter 3 (GLUT3) is up-regulated in human pregnancies complicated by late-onset intrauterine growth restriction. Placenta 34 1072-1078. (https://doi.org/10.1016/j. placenta.2013.08.010)

Joost H-G, Bell GI, Best JD, Birnbaum MJ, Charrron MJ, Chen YT, Doege H, James DE, Lodish HF, Moley KH, et al. 2002 Nomenclature of the GLUT/SLC2A family of sugar/polyol transport facilitators. American Journal of Physiology: Endocrinology and Metabolism 282 E974-E976. (https://doi.org/10.1152/ajpendo.00407.2001)

Jones HN, Crombleholme T \& Habli M 2013 Adenoviral-mediated placental gene transfer of IGF-1 corrects placental insufficiency via enhanced placental glucose transport mechanisms. PLOS ONE $\mathbf{8}$ e74632. (https://doi.org/10.1371/journal.pone.0074632)

Jones H, Crombleholme T \& Habli M 2014 Regulation of amino acid transporters by adenoviral-mediated human insulin-like growth factor- 1 in a mouse model of placental insufficiency in vivo and the human trophoblast line BeWo in vitro. Placenta 35 132-138. (https:// doi.org/10.1016/j.placenta.2013.11.012)

Kappes SM, Warren WC, Pratt SL, Liang R \& Anthony RV 1992 Quantification and cellular localization of ovine placental lactogen messenger ribonucleic acid expression during mid- and lategestation. Endocrinology 131 2829-2838. (https://doi.org/10.1210/ endo.131.6.1446621)

Lea RG, Wooding P, Stewart I, Hannah LT, Morton S, Wallace K, Aitken RP, Milne JS, Regnault TR, Anthony RV, et al. 2008 The expression of ovine placental lactogen, StAR and progesteroneassociated steroidogenic enzymes in placentae of overnourished growing adolescent ewes. Reproduction 135 889-889. (https://doi. org/10.1530/REP-06-0294e)

Limesand SW, Regnault TRH \& Hay WW Jr 2004 Characterization of glucose transporter 8 (GLUT8) in the ovine placenta of normal and growth restricted fetuses. Placenta 25 70-77. (https://doi. org/10.1016/j.placenta.2003.08.012)

Mando C, Tabano S, Pileri P, Colapietro P, Marino MA, Avagliano L, Doi P, Bulfamante G, Miozzo M \& Cetin I 2013 SNAT2 expression and http://joe.endocrinology-journals.org https://doi.org/10.1530/JOE-18-0093 (c) 2018 Society for Endocrinology Published by Bioscientifica Ltd. Printed in Great Britain 
regulation in human growth-restricted placentas. Pediatric Research $\mathbf{7 4}$ 104-110. (https://doi.org/10.1038/pr.2013.83)

Marconi AM, Paolini CL, Stramare L, Cetin I, Fennessey PV, Pardi G \& Battaglia FC 1999 Steady state maternal-fetal leucine enrichments in normal and intrauterine growth-restricted pregnancies. Pediatric Research 46 114-119. (https://doi.org/10.1203/00006450-19990700000019)

Meschia G, Battaglia FC \& Hay WW Jr \& Sparks JW 1980 Utilization of substrates by the ovine placenta in vivo. Federation Proceedings 39 245-249.

Pantham P, Rosario FJ, Weintraub ST, Nathanielsz PW, Powell TL, Li C \& Jansson T 2016 Down-regulation of placental transport of amino acids precedes the development of intrauterine growth restriction in maternal nutrient restricted baboons. Biology of Reproduction 9598. (https://doi.org/10.1095/biolreprod.116.141085)

Regnault TR, Friedman JE, Wilkening RB, Anthony RV \& Hay WW Jr 2005 Fetoplacental transport and utilization of amino acids in IUGR - a review. Placenta 26 (Supplement A) S52-S62. (https://doi. org/10.1016/j.placenta.2005.01.003)

Schmidt S, Joost HG \& Schurmann A 2009 GLUT8, the enigmatic intracellular hexose transporter. American Journal of Physiology: Endocrinology and Metabolism 296 E614-E618. (https://doi. org/10.1152/ajpendo.91019.2008)

Simpson IA, Dwyer D, Malide D, Moley KH, Travis A \& Vannucci SJ 2008 The facilitative glucose transporter GLUT3: 20 years of distinction. American Journal of Physiology: Endocrinology and Metabolism 295 E242-E253. (https://doi.org/10.1152/ajpendo.90388.2008)
Spellacy WN, Buhi WC \& Birk SA 1976 Human placental lactogen and intrauterine growth restriction. Obstetrics and Gynecology 47 446-448.

Taylor MJ, Jenkin G, Robinson JS, Thorburn GD, Friesen H \& Chan JS 1980 Concentrations of placental lactogen in chronically catheterized ewes and fetuses in late pregnancy. Journal of Endocrinology 85 27-34. (https://doi.org/10.1677/joe.0.0850027)

de Vrijer B, Regnault TR, Wilkening RB, Meschia G \& Battaglia FC 2004 Placental uptake and transport of ACP, a neutral nonmetabolizable amino acid, in an ovine model of fetal growth restriction. American Journal of Physiology: Endocrinology and Metabolism 287 E1114-E1124. (https://doi.org/10.1152/ajpendo.00259.2004)

Wali JA, de Boo HA, Derraik JGB, Phus HH, Oliver MH, Bloomfield FH \& Harding JE 2012 Weekly intra-amniotic IGF-1 treatment increases growth of growth-restricted ovine fetuses and up-regulated placental amino acid transporters. PLOS ONE 7 e37899. (https://doi. org/10.1371/journal.pone.0037899)

Walker WH, Fitzpatrick SL, Barrera-Saldana HA, Resendez-Perez D \& Saunders GF 1991 The human placental lactogen genes: structure, function, evolution and transcriptional regulation. Endocrine Reviews 12 316-328. (https://doi.org/10.1210/edrv-12-4-316)

Wooding F \& Burton G 2008 Comparative Placentation: Structures, Functions and Evolution. New York, NY, USA: Springer.

Wooding FBP, Fowden AL Bell AW, Ehrhardt RA, Limesand SW $\&$ Hay WW Jr 2005 Localisation of glucose transport in the ruminant placenta: implication for sequential use of transporter isoforms. Placenta 26 626-640. (https://doi.org/10.1016/j. placenta.2004.09.013)

Received in final form 12 April 2018

Accepted 16 April 2018

Accepted Preprint published online 16 April 2018 